\title{
EXPERIMENTAL INVESTIGATION ON EFFECT OF SKIRT
}

\section{ARRANGEMENT ON MODIFIED BOILING POT}

\author{
S. S. SINGH ${ }^{1}$, K. B. SAHU ${ }^{2} \&$ A. K. ROUT ${ }^{3}$ \\ ${ }^{I}$ Research Scholar, School of Mechanical Engineering, KIIT University, Odisha, India \\ ${ }^{2}$ Professor, School of Mechanical Engineering, KIIT University, Odisha, India \\ ${ }^{3}$ Associate Professor, School of Mechanical Engineering, KIIT University, Odisha, India
}

\section{ABSTRACT}

A lot of research work has been done in the literatures emphasizing on technical aspects of modified cook stoves; primarily on the performance and minimization of harmful emissions. But in published literatures limited investigation was made for improving boiling efficiency by using modified pot surfaces and use of skirts in boiling pots. In order to improve boiling efficiency, pot with modifications has greater impact to maintain balance between the technical capabilities and usability. This modification includes a low cost pot skirt that integrates directly with the standard flat bottomed pot. The effect of gap variation along the skirt on boiling efficiency at different heat input is investigated. Also the effect of aluminium foil on the skirt surface is investigated. Most of the researchers work on biomass stove for improving boiling efficiency, but there is limited work on Liquefied Petroleum Gas (LPG). Conducting the Water Boiling Test (WBT), it is identified that pot skirts improve boiling efficiency by $8-10 \%$ in all set of experiments and is observed maximum for a skirt gap of $8 \mathrm{~mm}$. The efficiency is further improved by using aluminium foil at the inner surface of the skirt. There is much less technical improvement on inexpensive energy efficient cookware. However these pot skirts could potentially improve boiling efficiency of cookware.

KEYWORDS: Boiling Pot, Pot Skirt, Insulated Skirt \& Boiling Efficiency

Received: Jun 08, 2018; Accepted: Jun 29, 2018; Published: Aug 11, 2018; Paper Id.: IJMPERDAUG2018106

\section{INTRODUCTION}

National Bureau of Statistics (2005) identifies that at present LPG is the common source of energy for industries as well as for domestic uses. In the industries the gas thermal efficiency is limited to $60 \%$ and the gas utilized for cooking in urban households in highly populated countries is about $27 \%$ of total consumption of gas. Also with the increase of population growth in the world, energy resources are decreased day by day, hence rise in energy costs. So, there is a growing need for efficient utilization of gas. Luo et al. (2010) found that heat loss to atmosphere from the gas burner is about $40 \%$ of the total heat of combustion while cooking which leads to poor thermal efficiency. Hence efficient utilization of heat released from gas combustion can significantly improve the thermal efficiency of a gas stove. Several studies were made by Karunanithy et al. (2016) on energy efficient cooking, using various cooktops such as electric coil, induction cook tops natural gas and. They observed that cooking efficiencies varies with the differences in the heating principles, pan shape, size, weight, material composition and bottom thickness. Kadam et al. (2017) conducted experiments by using five cylindrical shaped cooking pots with different heights to diameter ratio. They observed that conduction losses are more in case of pots with larger diameter since lot of amount of energy is used for heating pot. The height to diameter ratio also affects 
convection and radiation loss. Incropera FP. (2007) mentioned that the heat transfer efficiency is directly proportional to the energy absorbed by the cook pot. Convective heat transfer is the primary method of energy transfer in an improved biomass stove. Energy transfer through advection in the convection process is proportional to the fluid velocity. The effects of the thermal efficiency of different pot sizes were investigated by Naphon (2014). They conclude that the size of the cooking pots has less effect on the efficiency of the cooking pots. They found that though heat absorbing surface is more in larger pots convective heat loss is also higher due to exposure of larger surface to the surroundings. They found cooking pot with the helically coiled aluminum strip minimizes the convection heat loss and improves heat transfer rate. Thacker et al. (2017) improve the stove efficiency by modifying the traditional Peruvian channel stove by incorporating a different mechanism. They set a pot skirts which place on top of the cook stove which partly covering the cooking pot. They concluded that these pot skirts gave a considerable improvement in thermal efficiency during hot and cold starts which reduces fuel consumption, and boiling time. Joshi et al. (2012) analyzed using CFD that the insulation due to air gap between the covers reduces heat losses to the surroundings. The thermal efficiency decreases with increase in gap between the bottom of the cook pot and the burner top. It is also observed that when the temperature of water approaches boiling point there is a decrease of heat flux absorption by the cooking. Computational studies by Wohlgemuth et al. (2009) suggest that an optimum gap between pot and skirt. They also found that when the bottom edge of pot skirt is aligned with the mouth of the chimney better output can be obtained. They also observed that the skirt material does not play major role in altering the convective heat flux to the side of the pot rather the radiative heat flux. Dale Andreatta (2010) used a pot skirt and found that efficiency improved from $20.7 \%$ to $28.7 \%$ compared to pot without skirt positioned at an optimal gap between pot and skirt. Kirshagar (2009) designed a charcoal stove and observed that skirt gap of 8 mm improves efficiency by $3 \%$ where as large skirt gap of $17.5 \mathrm{~mm}$ efficiency reduce by $12 \%$. Nordica MacCarty et al. (2010) tested different stoves and observed that due to the presence of a pot skirt there was a reduction in fuel consumption and the emissions by $25-30 \%$ in comparison to the three-stone fire. Kumar et al. (2016) experimented with three different cook stove models and found that modified multi fuel cook stove without chimney and the stove had a combustion chamber with a skirt gave better performance than other types of cook stoves models. Dirker et al. (2005) observed that when annular diameter ratios were below 2.5, the correlation was agreed closely with those by Dittus and Boelter. The effect of pot gap and fluid flow geometry in a finned cooking pot on boiling efficiency with premixed and diffusion flames was investigated by D. J. Zube. (2010). He found that the premixed and diffused flames had least impact on heat transfer. He found that finned cooking surfaces gives better performance though it was not cost effective. Xue et al. (2015) investigated the boiling efficiency using two flue layers on the outside of the pot wall, where inner flue close to the pot by increasing gas flow rate by diverting the high temperature flue gas. The outer shield wall has the effect of heat preservation which has a ring of $15 \mathrm{~mm}$ diameter holes. He found that the flue gas flow up more close to the bottom of the pot and the pot wall increases the heat exchange area and the velocity which increases the heat transfer rate. The double hood increases the flue gas stay longer in the combustion zone, reducing the flue gas diffusion also has the effect of heat preservation.

\section{EXPERIMENTAL APPARATUS AND METHODS}

The experimental set up used in this investigation consists of a domestic LPG cylinder with a regulator and flow control valve. Digital weighing machine with least count $0.002 \mathrm{~kg}$ is used to measure initial and final weight of fuel to calculate the fuel consumed. Pots are cleaned, dried and weights are measured before conducting the experiments. The water boiling test (WBT) is conducted using $2 \mathrm{~kg}$ of distilled water in a room with minimum wind velocity. The cylindrical boiling pot having diameter $15 \mathrm{~cm}$ with height $15 \mathrm{~cm}$ is used for the test. Water is heated till it reaches its boiling point and 
the time taken for boiling is recorded. Temperature of water is recorded in an interval of 30 seconds. The pot skirt is covered the boiling pot to allow hot gasses to flow through the gap to minimize convective and radiative heat loss. Different skirt gap can be maintained using spacers and two adjustable rings. A thermocouple of type-T copper-constantan measures the temperature variation of water while conducting the experiment. It is fitted to the thermocouple holder so that tip of thermocouple probe can be positioned centrally inside the boiling pot at a height $2.5 \mathrm{~cm}$ above the base of the pot. All the data is recorded with a time interval of 30 seconds using a digital stopwatch.

\section{Boiling Pot}

The standard boiling pot is fabricated from $0.125 \mathrm{~cm}$ thick galvanized iron sheet with a dimension $15 \mathrm{x} 47.5 \mathrm{~cm}^{2}$. A cylindrical tube of $15 \mathrm{~cm}$ diameter is made from the sheet with height $15 \mathrm{~cm}$. Bottom of the container is flat circular sheet having diameter $15 \mathrm{~cm}$ is welded with the tube to make the bottom of the boiling pot. The boiling pot must be leak proof as no water will leaks away during boiling.

\section{Metal Pot Skirt}

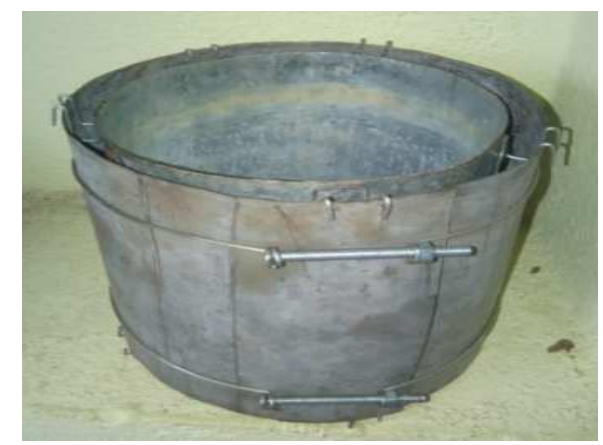

Figure 1: Standard Pot with Metal Skirt

The metal pot skirt is made from the same material that of boiling pot with a thickness $0.125 \mathrm{~cm}$ which surrounds the boiling pot. The provision for maintaining gap is made by using spacers and two adjustable rings as shown in Figure. 1.

\section{Skirt of Insulating Material}

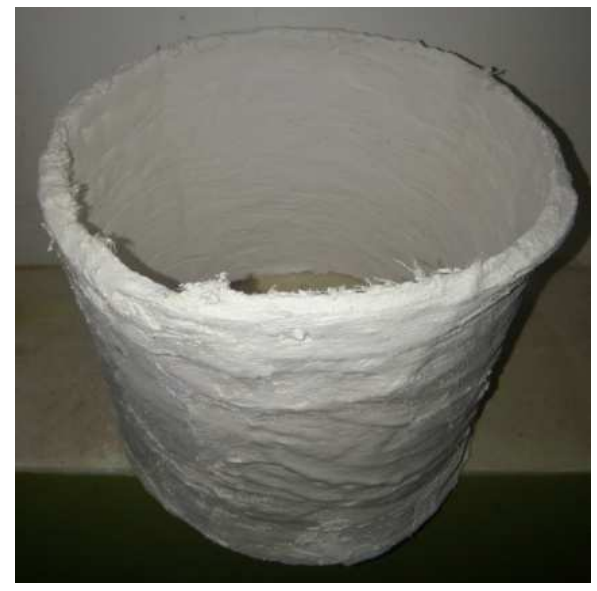

Figure 2(a): Insulated Skirt

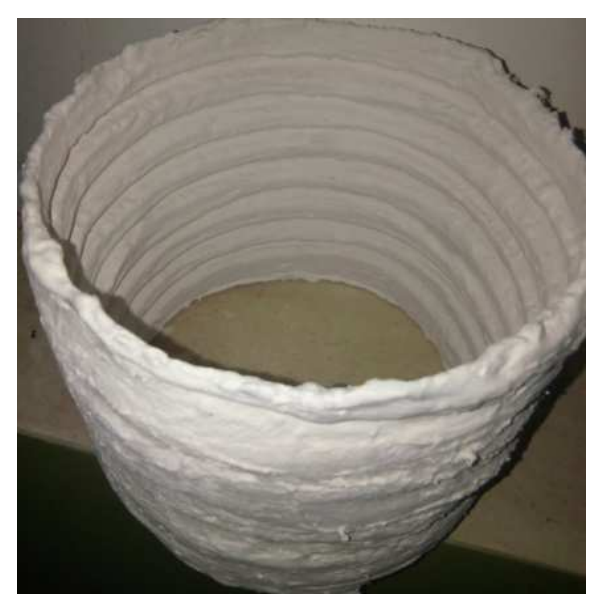

Figure 2(b): Insulated Grooved Skirt

Two different insulated skirts of thickness $0.8 \mathrm{~cm}$ and height $15 \mathrm{~cm}$ are casted from plaster of paris. The Figures 2a. and 2 b. show insulated skirt with internal diameter $16.6 \mathrm{~cm}$ and the internally grooved skirt with pitch diameter 16.6 
cm. respectively.

\section{Skirt with Reflecting Surface}

To make the skirt surface reflective aluminium foil is used at the sides of metal skirt. Separate skirt arrangements are made with a skirt gap of $0.8 \mathrm{~cm}$. Figure $3 \mathrm{a}$. shows that the foil is affixed at the outside surface of metal skirt and in Figure 3 b. foil is affixed at the inside surface the metal skirt.

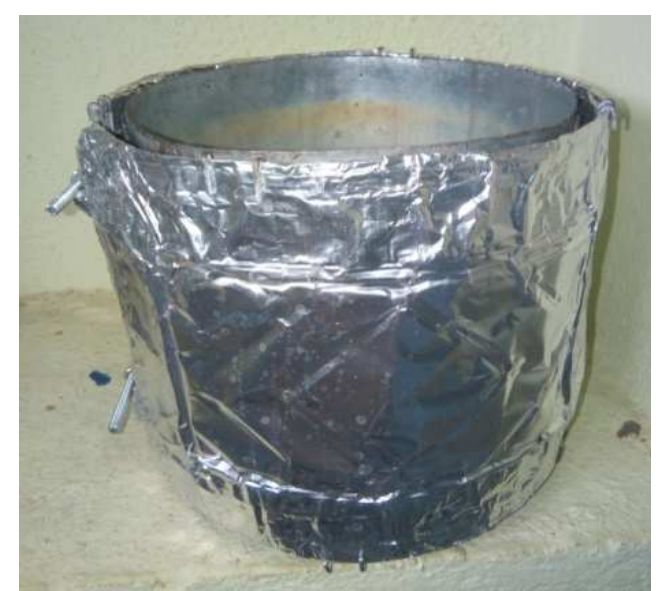

Figure 3(a): Aluminium Foil Outside the Metal Skirt

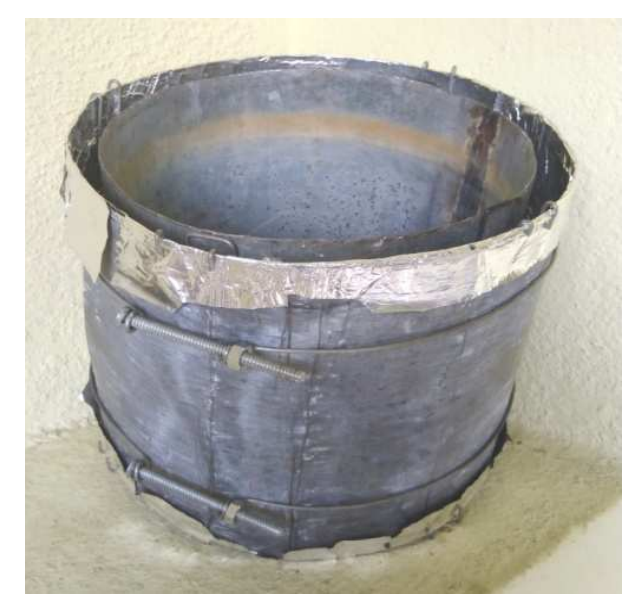

Figure 3(b): Aluminium Foil Inside the Metal Skirt

The WBT is carried out with different boiling pots with modified arrangements. Each set of experiments are conducted for a particular heat input. The heat input varies by controlling the gas flow rate for different set of experiments. Similar procedure is followed for different arrangements. The set of experiments carried out using:

- $\quad$ Standard pot (pot without skirt).

- Standard pot covered with a metal skirt having skirt gap $6 \mathrm{~mm}, \mathrm{~mm}, 12 \mathrm{~mm}$ and $16 \mathrm{~mm}$.

- Spiral finned pot covered with a metal skirt having skirt gap $8 \mathrm{~mm}$ from fin tip.

- $\quad$ Standard pot covered with insulated skirt having skirt gap $8 \mathrm{~mm}$.

- Standard pot covered with internally grooved insulated skirt having skirt gap $8 \mathrm{~mm}$.

- Standard pot covered with a metal skirt having annular gap ratios shown in Fig. 6 (ratio between skirt gap at bottom and top of the pot) $8: 8,8: 6,8: 4,12: 12,12: 8,12: 6$ and $12: 4$ with gas flow rate $0.002 \mathrm{~kg} / \mathrm{min}$.

- A covering of aluminium foil over the metal skirt.

Boiling efficiency $(\eta)$, which is the part of heat produced by the fuel transferred to the water present in the pot till boiling, can be calculated using equation

$$
\eta=\frac{m_{w} C_{p}\left(T_{2}-T_{1}\right)}{C V_{f} m_{f}} \times 100 \%
$$

where $T_{1}$ and $T_{2}$ are initial and final temperature of water in ${ }^{\circ} \mathrm{C} . m_{w}$ and $m_{f}$ represent weight of water before the test and the amount of gas consumed in $\mathrm{kg}$ respectively. Specific heat water at constant pressure $C_{p}$ is $4.186 \mathrm{~kJ} / \mathrm{kg}^{\circ} \mathrm{C}$. 
Lower heating value, $C V_{f}$ of consumed LPG is $49 \mathrm{MJ} / \mathrm{kg}$. The boiling efficiency is increased by reducing the fuel consumption. So maximizing the utilization of fuel reduces fuel consumption.

\section{RESULTS AND DISCUSSIONS}

The variation of temperature with time for different skirt gap using metal skirt at a particular gas flow rate $0.002 \mathrm{~kg} / \mathrm{min}$ is shown in Figure 4. Attainment of boiling point of water depends on amount of rate of heat received by the water. It is observed that distilled water in the pot having $8 \mathrm{~mm}$ skirt gap reaches its boiling point much earlier than other pots with different skirt gap.

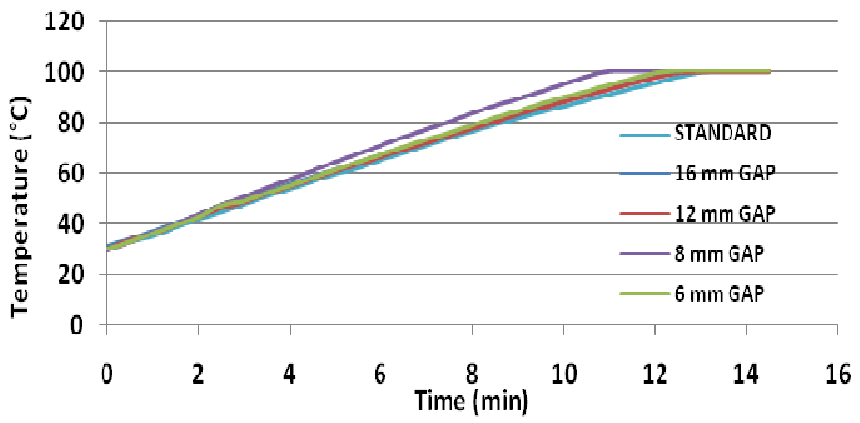

Figure 4: Change in Temperature with Time at a Gas Flow Rate 0.002 kg/min

When the skirt gap increases the time taken to attain its boiling point also increases. Heat loss due to convection and radiation is more in standard pot so it takes more time to reach its boiling point compared to pots with skirt. For a given flow rate, the convection heat transfer at the bottom surface remains same. But the amount of flue gas not in contact with the lateral surface depends on the skirt gap. When the skirt gap is less, the flue gas which tends to go away is deflected back by the skirt towards the lateral surface. When the skirt gap is more beyond a limit, the flue gas is not deflected back to the lateral surface. The time taken for reaching boiling point is gradually less for skirt gap of $16 \mathrm{~mm}, 12$ $\mathrm{mm}$. The minimum time is taken for the case of $8 \mathrm{~mm}$ skirt gap to reach the boiling temperature and again the time taken is increased for the case of $6 \mathrm{~mm}$ skirt gap. For higher skirt gaps $(16 \mathrm{~mm}$ and $12 \mathrm{~mm})$ the flue gas passes through the skirt gap adjacent to the skirt and heat is not transferred to the pot effectively. At $8 \mathrm{~mm}$ skirt gap, the flue gas is redirected by the skirt towards the outer surface of the pot and the heat is transferred effectively. But due to very less gap between the pot bottom and skirt at $6 \mathrm{~mm}$ skirt gap, much of the flue gas flows outside the skirt and heat of flue gas is lost to the surroundings.

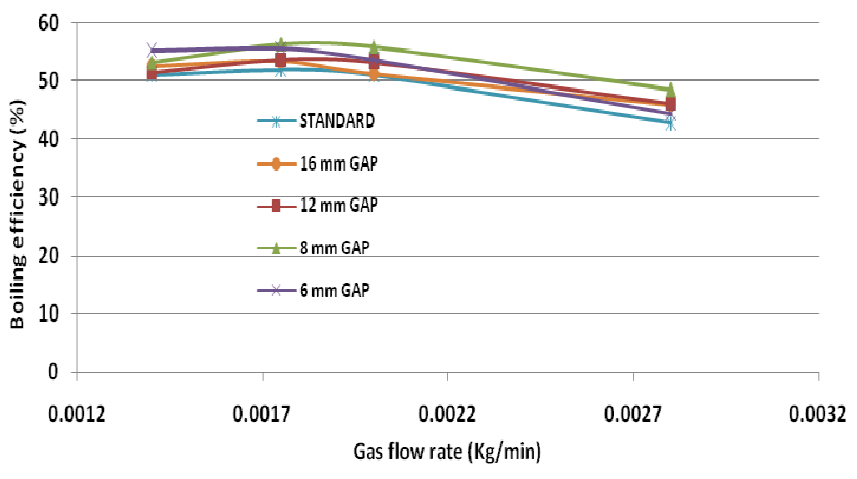

Figure 5: Effect of Skirt gap on Boiling Efficiency 
Figure 5. shows variation of boiling efficiency with gas flow rate for different skirt gap. It is observed that at low gas flow rate, the velocity of flue gas is less for which the convection heat transfer is less. As the flow rate of gas increases, the velocity of flue gas increases and the convection heat transfer from bottom and lateral surfaces becomes more. So, boiling efficiency increases with the gas flow rate. As gas flow rate further increases, the convective heat transfer at bottom surface increases, but the amount of flue gas not in contact with the lateral surface of pot increases. So, the boiling efficiency decreases beyond an optimum gas flow rate. The boiling efficiency is always more for pots with metal skirt compared to the standard pot. But the boiling efficiency increases as the skirt gap increases to an optimum value and then decreases as the reason explained earlier. At lowest gas flow rate taken in this study, the boiling efficiency is the maximum for the case of $6 \mathrm{~mm}$ skirt gap. This is because the velocity of the flue gases is low due to low gas flow rate and the entire flue gas passes through the skirt which is redirected by the skirt towards the outer surface of the pot.

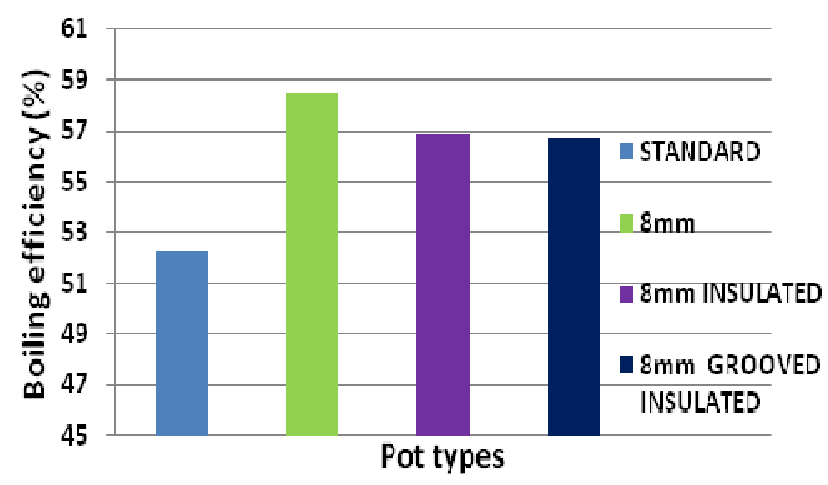

Figure 6: Boiling Efficiency of Different Insulated Pot Skirts

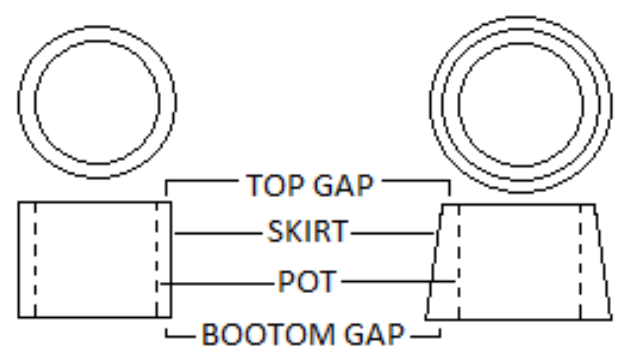

Figure 7: Schematic Diagram of Skirt Gap at Bottom and Top of the Pot

Using different insulated skirts with a gas flow rate $0.002 \mathrm{~kg} / \mathrm{min}$, the results are recorded and compared with standard pot with skirt and without skirt as shown in Figure 6. All skirted pots are maintained with a skirt gap of 8 mm. The efficiency of pots with insulated skirt is less compared to that of pots with metal skirt. This is because the insulated skirt absorbs a significant amount of heat from the flue gas due to its thickness. It also shows that there is no significant change in boiling efficiency when shape of insulation varies. But the boiling efficiency of skirted pots is more than standard pot. A schematic diagram of skirt gap at bottom and top of the pot is shown in Figure 7. 


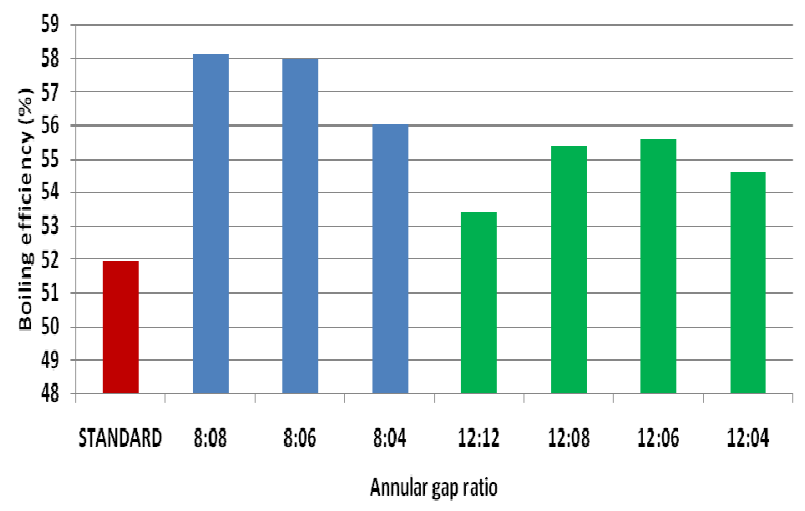

Figure 8: Variation of Boiling Efficiency at Different Annular Skirt Gap Ratio

Pots with metal skirt having different annular gap ratio (bottom gap to top gap) is investigated at a given gas flow rate $(0.0019 \mathrm{~kg} / \mathrm{min})$ and their boiling efficiency is compared as shown in Figure 8 . It is depicted from the figure that while maintaining the annular gap ratio of 8:8 the efficiency is better compared to gap ratio 8:6 and 8:4. When the skirt gap is reduced at the top, flow velocity is reduced due to restriction in the flow passage of the flue gases and more flue gas flows outside the skirt due to backflow For the bottom skirt gap of $12 \mathrm{~mm}$, it is observed that for annular gap ratio of 12:12, the efficiency is poor compared to other annular gap ratios. As the top gap is decreased ( $8 \mathrm{~mm}$ and $6 \mathrm{~mm}$ ), the efficiency increases, but the efficiency decreases with further decrease in the top gap (4 mm). As the top gap is reduced up to $6 \mathrm{~mm}$, the efficiency is increased due to deflection of flue gas towards the pot surface, but with further decrease in top gap the efficiency decreases due to flow restriction as explained earlier.

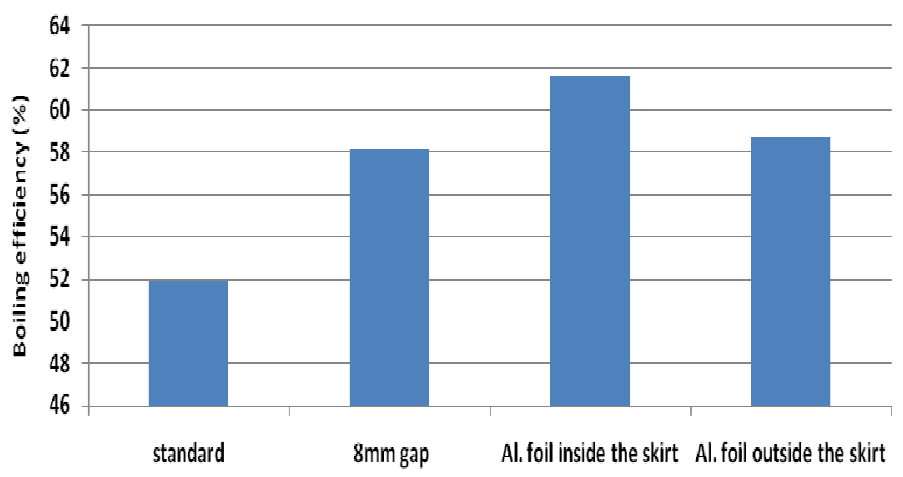

Figure 9: Boiling Efficiency of Water using Aluminium Foil at Different Sides of Metal Skirts

Figure 9 shows the effect of aluminium foil at the sides of metal skirt on boiling efficiency. Aluminum foil has been used in this study as a reflective surface. The pot with aluminium foil at the inside surface of the skirt reflects greater amount of heat thereby reducing the radiation heat loss. So the boiling efficiency in this case is better than that of the others. When the foil is placed outside the skirt, the heat is conducted by the metal skirt and the temperature of the aluminium foil at the outside is more for which radiation loss is more compared to that with foil placed inside the surface of skirt. But the efficiency of pot with aluminium foil at outer surface of skirt is more compared to that of pot with metal skirt as the radiation loss to the surrounding from the skirt is reduced. 


\section{CONCLUSIONS}

The boiling efficiency of distilled water using boiling pot having bottom diameter $15 \mathrm{~cm}$ with different skirt arrangements has been investigated. The conclusions may be made as follows:

- For a given gas flow rate, the boiling temperature of distilled water reached early in the pot having skirt gap of 8 mm compared to all other pots including standard pot. So, pots with an optimum skirt gap are more effective.

- With the increase in gas flow rate the boiling efficiency first increases and then decreases for all set of pot and skirt arrangements. There is an optimum gas flow rate for each case at which the boiling efficiency is maximum.

- The boiling efficiency of pots with skirt is more compared to that of pot without skirt.

- There is no improvement in boiling efficiency while using pots with insulated skirts compared to pots with metal skirt.

- The boiling efficiency increases with decrease in the top skirt gap to an optimum value for higher bottom gap (12 $\mathrm{mm})$.

- $\quad$ But the boiling efficiency decreases continuously with decrease in the top skirt gap for lower bottom gap (8 mm).

- The boiling efficiency of pots with reflecting skirt inner surface is more compared to that of pots with reflecting skirt outer surface.

\section{REFERENCES}

1. National Bureau of Statistics. (2005). China statistical yearbook 2005, China Statistics Press.2005.

2. Congjie Luo, Xiaohong Yang, Jing Liao. (2010). The ways to improve thermal efficiency of atmospheric type domestic gas cooking appliances, Energy research and management, No. 02, (pp.69-71).

3. Karunanithy, C. Shafer, K. (2016). Heat transfer characteristics and cooking efficiency of different saucepans on various cooktops, Applied Thermal Engineering, 93 (pp. 1202-1215).

4. Purushottam Kadam, J. P. Shete. (2017). Experimental Study of Heat Transfer Characteristics and Thermal Efficiency of Different Cooking Pots, International Journal of Scientific Development and Research, 2(12).

5. Incropera, FP. (2007). Introduction to heat transfer, Wiley: Hoboken, N.J. 2007.

6. Paisarn Naphon. (2014). Thermal Efficiency Enhancement of Domestic Cooking Pots, Asian Journal of Engineering and Technology, 02 (05).

7. Thacker, Kendall . B. Barger, K. McCall. Mattson, Chistopher A. (2017). Balancing technical and user objectives in the redesign of a peruvian cook stove, Development engineering, 2 (pp. 12-19).

8. Jyeshtharaj, B. Joshi. et al. (2012) Development of Efficient Designs of Cooking Systems. II. Computational Fluid Dynamics and Optimization, Industrial Engineering Chemistry Research, 51(4), (pp.1897-1922).

9. Wohlgemuth, Alex. Mazumdar, Sandip. Andreatta, Dale. (2009). Computational heat transfer analysis of the effect of skirts on the performance of third world cook stove, Journal of Thermal Science and Engineering Applications, 1(04).

10. D. Andreatta and Wohlgemuth, A. (2010). An Investigation of Skirts. 
11. Kshirsagar, Milind Prakash. (2009). Experimental study for improving energy efficiency of charcoal stove, Journal of Scientific \& Industrial Research, 68 (pp. 412-416).

12. Maccarty, N. Still, D. and Ogle, D. (2010). Fuel use and emissions performance of fifty cooking stoves in the laboratory and related benchmarks of performance, Energy for sustainable development, 14(3) (pp.161-171).

13. Sankar, A. R., Gunakala, S. R., \& Comissiong, D. M. The Effect Of Heat Transfer On Two-Layered Blood Flow Through A Composite Stenosis In The Presence Of A Magnetic Field.

14. Kumar, Arvind and Mishra, K.P. (2016). Development of Energy Efficient Cooking Systems for Rural Masses, International Journal of Scientific Development and Research (IJSDR), 1(4) ( pp. 115-121).

15. Dirker, J. and MEYER, J. P. (2005).Convective Heat Transfer Coefficients in Concentric Annuli, Heat Transfer Engineering, 26(2), (pp. 38-44).

16. Zube, MS. (2010). Heat Transfer Efficiency Biomass Cookstoves, Thesis, Colorado State University, 2010.

17. Xue, Xing. Wang, Fengjuan and Fenglan, Wei. (2015). The Improvement Research of Commonly Used Gas Pot with Numerical Simulation, 2nd International Forum on Electrical Engineering and Automation (IFEEA 2015). 
